\title{
Effects of Surface Activity on Aquatic Toxicity of Binary Surfactant Mixtures
}

\author{
Noriko Hisano ${ }^{1}$ and Masaru Oya ${ }^{2 *}$ \\ ${ }^{1}$ Graduate School of Environment and Information Sciences, Yokohama National University (79-7 Tokiwadai, Hodogaya-ku, Yokohama 240-8501, \\ JAPAN) \\ ${ }^{2}$ Faculty of Education and Human Sciences, Yokohama National University (79-2 Tokiwadai, Hodogaya-ku, Yokohama 240-8501, JAPAN)
}

\begin{abstract}
The purpose of this study was to discuss the effects of surface activity on the aquatic toxicity of binary surfactant mixtures comprising anionic, nonionic, and cationic surfactants. Surface tension was measured to determine the cmc (critical micelle concentration), and acute aquatic toxicity tests were conducted on Daphnia magna to obtain $24 \mathrm{~h}-\mathrm{EC}_{50}(24 \mathrm{~h} 50 \%$ effective concentration). TU (toxic unit) was calculated to evaluate the toxicity of the mixture. Most of the surfactant mixtures showed no synergistic increase in the aquatic toxicity. The mixture of anionic/nonionic surfactants showed synergistic interfacial activity with decreasing cmc, but the toxicity did not increase. The surface tension of the mixture at $24 \mathrm{~h}-\mathrm{EC}_{50}\left(\gamma_{\text {tox }}\right)$, which was used as an indicator of the toxic concentration, decreased considerably and TU was $>1$, indicating decreased toxicity. $\gamma_{\text {tox }}$ of the anionic/anionic surfactant mixture decreased when tested with hard water (hardness of $625 \mathrm{ppm}) \cdot \gamma_{\text {tox }}$ could not be used as a toxic indicator for the anionic/cationic surfactant mixtures because they showed aquatic toxicity before their surface tension began to decrease.
\end{abstract}

Key words: surface tension, $\mathrm{EC}_{50}$, water hardness, anionic surfactant, nonionic surfactant, cationic surfactant

\section{INTRODUCTION}

It is widely known that the toxicity of surfactants increases when the cellular permeability of aquatic species increases in response to decreased surface tension. This causes the surfactants and other chemical substances to enter the environment ${ }^{1)}$. Therefore, environmental modifying factors such as water hardness, temperature, and chemical substances and adsorbents that affects the surface tension can influence the aquatic toxicity of surfac$\operatorname{tants}^{2-4)}$. In our previous study, we focused on water hardness and the presence of adsorbents to discuss the effects of water properties on the aquatic toxicity of anionic and nonionic surfactants using surface tension as an indicator of the interfacial activity of the surfactants ${ }^{5}$. The surface tension value at $24 \mathrm{~h} 50 \%$ effective concentration $\left(24 \mathrm{~h}-\mathrm{EC}_{50}\right)$ was defined as $\gamma_{\text {tox }}$. When the same type of surfactant and test organism was used, $\gamma_{\text {tox }}$ remained constant, even when $\mathrm{EC}_{50}$ was varied by changing the water hardness and/or the amount of adsorbent. Therefore, we confirmed that surface tension can be a good indicator of the aquatic toxicity of a surfactant.

Several researchers have reported that the interfacial activity of surfactant mixtures increases depending on their ionic characteristics, the type of surfactant used, the mixing ratio, and the test conditions in the mixture ${ }^{6)}$. In particular, the interfacial activity of anionic/nonionic mixed surfactant systems has often been studied owing to their wide usage in industrial and household applications ${ }^{7,8)}$. Abe and Ogino ${ }^{8}$ found that the critical micelle concentration (cmc) of a mixture of sodium dodecyl sulfate (SDS) and alkyl polyoxyethylene (alkyl chain length: 18, number of POE units: 20) was much lower than that of SDS alone. Anionic/ anionic surfactant mixtures are also widely used because their physical properties such as solubility can be efficiently controlled in the mixture ${ }^{9)}$. Although the physical properties of surfactant mixtures have been well studied, less focus has been placed on their aquatic toxicity.

Lewis et $a l .{ }^{10)}$ studied the aquatic toxicity of binary and ternary surfactant mixtures of anionic, nonionic, and cationic surfactants using Daphnia magna and Lepomis macrochirus. They measured the toxicity of surfactant mixtures in terms of toxic units and the additive index and found that it was generally less than (decrease in toxicity) or equal to (no synergistic increase or decrease in toxicity)

\footnotetext{
*Correspondence to: Masaru Oya, Faculty of Education and Human Sciences, Yokohama National University, 79-2 Tokiwadai, Hodogaya-ku, Yokohama 240-8501, JAPAN

E-mail: moya@ynu.ac.jp

Accepted May 11, 2010 (received for review March 23, 2010)

Journal of Oleo Science ISSN 1345-8957 print / ISSN 1347-3352 online

http://www.jstage.jst.go.jp/browse/jos/
} 


\section{N. Hisano and M. Oya}

Table 1 Combination of ionicity and kind of surfactant used in each test

\begin{tabular}{ccc}
\hline Ionicity & water hardness 25ppm & water hardness 625ppm \\
\hline Anionic/Anionic & LAS/AS, LAS/SOAP & LAS/AS \\
\hline $\begin{array}{c}\text { Anionic/Nonionic } \\
\text { (general) }\end{array}$ & LAS/AE9, AS/AE9 & \\
Anionic/Nonionic & LAS/AE6, LAS/AE12 & LAS/AE9 \\
(effect of EO units length) & LAS/AE18 & \\
\hline Anionic/Cationic & LAS/HTAC & LAS/HTAC \\
\hline
\end{tabular}

the additive toxicity of the individual surfactants. However, researchers including Lewis et al. have not discussed toxicity from the viewpoint of interfacial activity, which is the main cause of aquatic toxicity of surfactants. If the increased interfacial activity of a surfactant mixture can directly affect the aquatic toxicity, the toxicity of surfactant mixtures may increase. Therefore, the interfacial activity of surfactants and factors that can increase the interfacial activity such as mixing ratio and water properties should also be discussed.

In this study, we discussed the aquatic toxicity of binary surfactant mixtures comprising anionic, nonionic, and cationic surfactants and used surface tension as an indicator of the surface activity. D. magna was used as the test organism to determine the aquatic toxicity at $24 \mathrm{~h}-\mathrm{EC}_{50}$. To investigate the relationship between the surface activity and aquatic toxicity, $\gamma_{\text {tox }}$ was used as an indicator of the point at which toxicity emerges $\left(24 \mathrm{~h}-\mathrm{EC}_{50}\right)$. Each ionic/ionic and ionic/nonionic surfactant mixture was evaluated at three different mixing ratios. Further, we investigated the effects of the length of the hydrophilic group of nonionic surfactants and the change in hardness of the test water on toxicity.

\section{EXPERIMENTAL PROCEDURE}

\subsection{Surfactants and mixed surfactants}

Three anionic surfactants, four nonionic surfactants, and one cationic surfactant were used in this study. The three anionic surfactants were LAS (sodium linear alkylbenzene sulfonate, Wako Chemical Co., used for a laundry detergent test in JIS, Assay >95\%), AS (sodium dodecyl sulfate, Wako Chemical Co., Assay (GC) >95\%), and SOAP (sodium oleate, Wako Chemical Co., Assay (GC)>60\%). The carbon number distribution of LAS obtained by HPLC analysis was as follows: $\mathrm{C}_{10}: 15.9 \%, \mathrm{C}_{11}: 33.2 \%, \mathrm{C}_{12}: 30.3 \%$, and $\mathrm{C}_{13}: 20.54 \%$. The four nonionic surfactants used were AE9 (alcohol ethoxylates, C:12, EO: 9, Wako Chemical Co.), AE6 (alcohol ethoxylates, C:13, EO: 6, Sigma-Aldrich Co.), AE12 (alcohol ethoxylates, C:13, EO:12, Sigma-Aldrich Co.), AE18 (alcohol ethoxylates, C:13, EO:18, Sigma-Al- drich Co.). Additionally, the cationic surfactant used was HTAC (hexadecyltrimethylammonium chloride, Wako Chemical Co.).

The combination of ionicity, types of surfactant used in the mixtures, and water hardness are shown in Table 1. Surface tension measurements and acute aquatic toxicity tests were conducted on each surfactant mixtures at a mixing ratio of $0: 10,3: 7,5: 5,7: 3$, and $10: 0$ by weight.

\subsection{Test water}

Standard test water with hardness of $25 \mathrm{ppm}$ as $\mathrm{CaCO}_{3}$ was prepared by dissolving $26.1 \mathrm{mg}$ of $\mathrm{CaCl}_{2} \cdot 2 \mathrm{H}_{2} \mathrm{O}, 17.7$ $\mathrm{mg}$ of $\mathrm{MgSO}_{4} \cdot 7 \mathrm{H}_{2} \mathrm{O}, 1.1 \mathrm{mg}$ of $\mathrm{K}_{2} \mathrm{SO}_{4}$, and $25 \mathrm{mg}$ of $\mathrm{NaH}-$ $\mathrm{CO}_{3}$ in $1 \mathrm{~L}$ of distilled water. In addition, test water at a water hardness of $625 \mathrm{ppm}$ based on the $\mathrm{CaCO}_{3}$ concentration was prepared using twenty-five times more of each of the water hardness components used to prepare the test water with a water hardness of $25 \mathrm{ppm}$.

\subsection{Surface tension test}

EZ-Pi (Kibron Inc.) with a platinum wire probe was used to measure the surface tension of the test solution by the Wilhelmy balance method. The temperature of the test water was controlled between $20^{\circ} \mathrm{C}$ and $22^{\circ} \mathrm{C}$, and it was allowed to stand for more than 20 min before the measurement to stabilize its surface. The surface tension value of the surfactant at $24 \mathrm{~h}-\mathrm{EC}_{50}$ was then determined and reported as $\gamma_{\text {tox }}$.

\subsection{Acute aquatic toxicity test}

A toxicity test was performed according to JIS K 0229 (1992), and D. magna was used as the test organism. To use larval organisms born within $24 \mathrm{~h}$ of the test, the adult organisms were transferred to breeding vessels $24 \mathrm{~h}$ prior to the test ${ }^{6)}$. A total of $9.5 \mathrm{~mL}$ of test water and test surfactant solution were poured in a $20 \mathrm{~mL}$ volumetric glass tube. Five test organisms were then transferred into each test tube and distilled water was added to the $10 \mathrm{~mL}$ line. Four test tubes were prepared for each concentration of the sample, and two test tubes without surfactant were prepared for the blank test. The tubes were then incubated under a $16 \mathrm{~h} / 8 \mathrm{~h} \mathrm{light/dark}$ cycle at $20^{\circ} \mathrm{C}$ to $22^{\circ} \mathrm{C}$ for $24 \mathrm{~h}$, 
after which the dead and immobilized individuals were counted. Next, the immobilization rate was calculated by dividing the number of dead and immobilized individuals by the number of total individuals. Next, $24 \mathrm{~h}-\mathrm{EC}_{50}$ was determined by graphical plotting of the immobilization rates against the surfactant concentration.

\subsection{Toxic unit concept}

The toxic unit (TU) is an indicator of toxicity that is defined as the actual concentration in solution divided by the lethal threshold concentration ${ }^{11)}$. To determine the toxicity of a mixture, the toxic units of each surfactant were added together using the following equation ${ }^{12)}$ :

$(\mathrm{Am} / \mathrm{Ai})+(\mathrm{Bm} / \mathrm{Bi})=\mathrm{TU}$

where $\mathrm{Ai}$ is the $\mathrm{EC}_{50}$ value for surfactant $\mathrm{A}$ alone, $\mathrm{Bi}$ is the $\mathrm{EC}_{50}$ value for surfactant $\mathrm{B}$ alone, $\mathrm{Am}$ is the concentration of surfactant A in the surfactant mixture, and Bm is the concentration of surfactant B in the surfactant mixture. The TU of surfactant $\mathrm{A}(=\mathrm{Am} / \mathrm{Ai})$ and surfactant $\mathrm{B}(=\mathrm{Bm} /$ $\mathrm{Bi}$ ) were added together to express the TU of the surfactant mixture. If the TU is equal to 1 , the toxicity is simply additive (no synergistic increase or decrease in toxicity), while the toxicity is less-than-additive (synergistic decrease in toxicity) if the TU is greater than 1 and it is greater-thanadditive (synergistic increase in toxicity) if it is less than 1.

\section{RESULTS AND DISCUSSION}

\subsection{Surface activity and aquatic toxicity of individual surfactants}

The cmc was used to evaluate the surface activity and $24 \mathrm{~h}-\mathrm{EC}_{50}$ among groups was compared to evaluate the aquatic toxicity of individual surfactants (Table 2). LAS showed the highest surface activity of the three anionic surfactants, with the lowest $\mathrm{cmc}(100 \mathrm{mg} / \mathrm{L})$. The cmc val-
Table 2 Critical micelle concentration $(\mathrm{cmc})$ and $24 \mathrm{~h}-\mathrm{EC}_{50}$ of test surfactants

\begin{tabular}{ccc}
\hline Surfactant & $\mathrm{cmc}(\mathrm{mg} / \mathrm{L})$ & $\mathrm{EC}_{50}(\mathrm{mg} / \mathrm{L})$ \\
\hline LAS & 100 & 10 \\
AS & 500 & 34 \\
SOAP & 560 & 4 \\
\hline AE9 $(\mathrm{C}=12)$ & 56 & 3 \\
AE6 $(\mathrm{C}=13)$ & 50 & 4.5 \\
AE12 $(\mathrm{C}=13)$ & 180 & 27 \\
AE18 $(\mathrm{C}=13)$ & 320 & 50 \\
\hline HTAC & 180 & 0.01 \\
\hline
\end{tabular}

ues of the other two anionic surfactants, AS (500 mg/L) and $\operatorname{SOAP}(560 \mathrm{mg} / \mathrm{L})$, were relatively close and much higher than that of LAS. Despite the high surface activity, the toxicity of LAS was lower than that of SOAP. With a water hardness of $25 \mathrm{ppm}$, SOAP showed the strongest toxicity among the three anionic surfactants, while AS showed the weakest toxicity. The nonionic surfactants, AE9 and AE6, showed higher surface activity and stronger aquatic toxicity than AE12 and AE18, which had longer EO chain lengths. These findings are similar to those reported by Kikuchi $^{13)}$, who found that the toxicity of C12-AE to Oryzias latipes increased as the EO unit increased from 3 to 16 . Based on the results obtained with AE9 and AE6 in the present study, the difference in toxicity caused by the difference in EO chain length was not apparent because their alkyl chain lengths were different (AE9, C=12; AE6, C = 13). The cmc of the cationic HTAC was about $180 \mathrm{mg} / \mathrm{L}$, which was similar to that of $\mathrm{AE} 12$, while $24 \mathrm{~h}-\mathrm{EC}_{50}$ was significantly low as expected because HTAC is often contained in pesticides.

Table 3 Critical micelle concentration (cmc), $24 \mathrm{~h}-\mathrm{EC}_{50}$, and TU of anionic/ anionic surfactant mixtures at water hardness of $25 \mathrm{ppm}$

\begin{tabular}{ccccc}
\hline & Mixed ratio & $\mathrm{cmc}(\mathrm{mg} / \mathrm{L})$ & $\mathrm{EC}_{50}(\mathrm{mg} / \mathrm{L})$ & $\mathrm{TU}$ \\
\hline LAS/AS & $10: 0$ & 100 & 10 & 1.00 \\
& $7: 3$ & 180 & 12 & 0.91 \\
& $5: 5$ & 180 & 12 & 0.74 \\
& $3: 7$ & 320 & 12 & 0.58 \\
\hline LAS/SOAP & $0: 10$ & 500 & 34 & 1.00 \\
& $10: 0$ & 100 & 10 & 1.00 \\
& $7: 3$ & 100 & 9 & 1.31 \\
& $5: 5$ & 320 & 7.5 & 1.31 \\
& $3: 7$ & 560 & 11 & 2.26 \\
& $0: 10$ & 560 & 4 & 1.00 \\
\hline
\end{tabular}


3.2 Relationship between surface tension and aquatic toxicity of binary surfactant mixture for varying ionicity and mixing ratio

3.2.1 Anionic/anionic surfactant mixture

The $\mathrm{cmc}$ was used to evaluate the surface activity and the TU values were compared to evaluate the aquatic toxicity. Additionally, the $\gamma_{\text {tox }}$ was used to discuss the relationship between surface activity and aquatic toxicity.

The change in cmc and TU of LAS/AS and LAS/SOAP with different mixing ratios is shown in Table 3. The cmc values of LAS/AS increased as the ratio of AS in LAS/AS increased. The aquatic toxicity of LAS/AS was slightly greater than additive. The 3:7 mixture showed the greatest toxicity, as indicated by a TU value was 0.58 , while that of the 7:3 mixture was 0.91 and that of the 5:5 mixture was 0.74 . On the other hand, the toxicity of LAS/SOAP was less than additive and the decrease in toxicity was greater for the $3: 7$ mixture, as indicated by a TU value of 2.26 . These findings indicate that small amounts of LAS have a relatively strong influence upon the toxicity of the LAS/anionic mixture.

Figures 1 and 2 show the $\gamma_{\text {tox }}$ of LAS/AS and LAS/SOAP, which is the surface tension value at the concentration corresponding to $24 \mathrm{~h}-\mathrm{EC}_{50}$. The $\gamma_{\text {tox }}$ of the mixtures changed depending on the mixing ratio of the LAS/AS, but the $\gamma_{\text {tox }}$ of LAS/SOAP was almost the same. Therefore, the $\gamma_{\text {tox }}$ change in the anionic/anionic surfactant mixtures varies depending on the type of surfactant used. However, a characteristic tendency was observed in both mixtures in which the $\gamma_{\text {tox }}$ values were lower than that of AS or SOAP and higher than

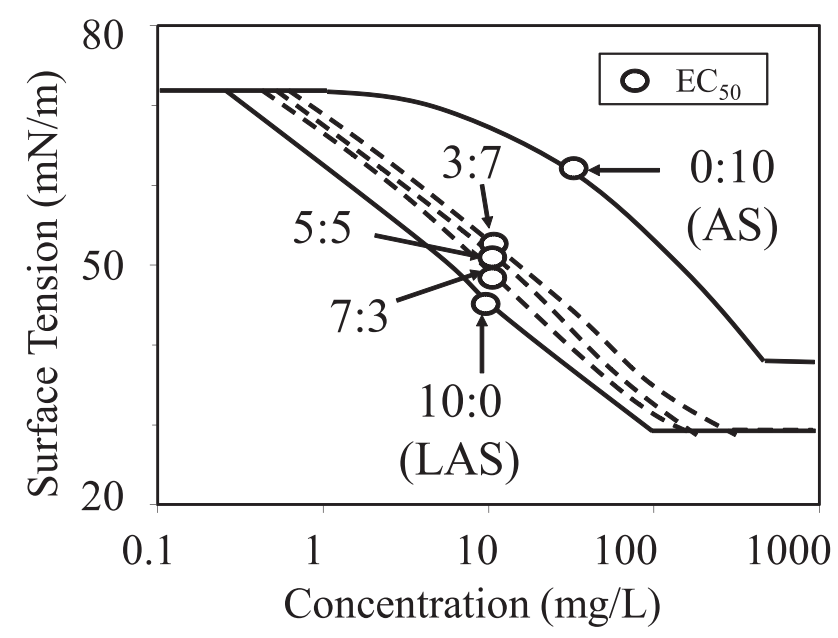

Fig. $1 \gamma$ vs concentration curves for LAS/AS mixtures with different mixing ratios.

Solid lines and dashed lines represent the individual surfactants and the surfactant mixtures, respectively. Circles on each curve represent the points corresponding to $\gamma_{\text {tox }}$, i.e., the surface tension at $24 \mathrm{~h}-\mathrm{EC}_{50}$.

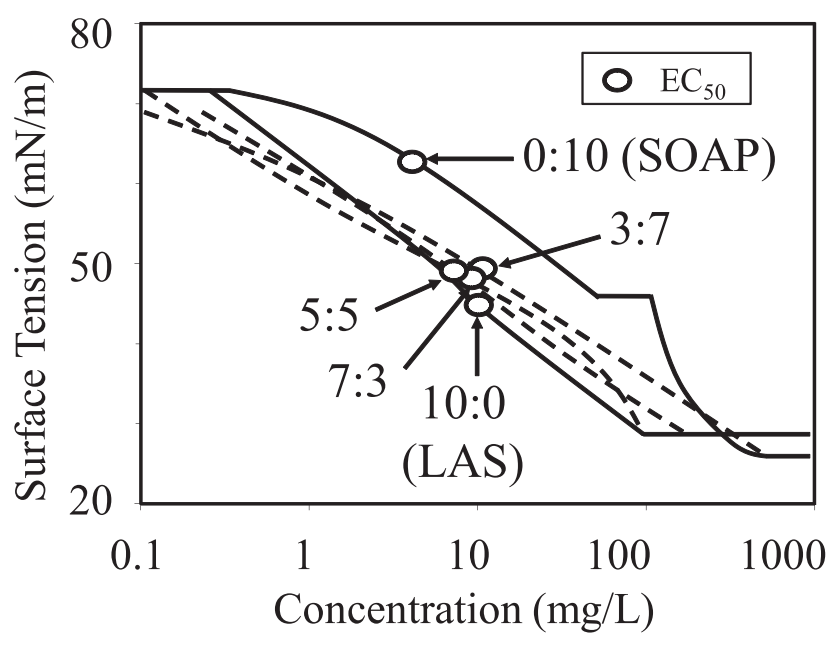

Fig. $2 \gamma$ vs concentration curves for LAS/SOAP mixtures with different mixing ratios.

Solid lines and dashed lines represent the individual surfactants and the surfactant mixtures, respectively. Circles on each curve represent the points corresponding to $\gamma_{\text {tox }}$, i.e., the surface tension at $24 \mathrm{~h}-\mathrm{EC}_{50}$.

that of LAS. For example, the $\gamma_{\text {tox }}$ values of LAS/AS ranged from 48 to $52 \mathrm{mN} / \mathrm{m}$, while those of LAS and AS were 45.7 $\mathrm{mN} / \mathrm{m}$ and $62 \mathrm{mN} / \mathrm{m}$, respectively (Fig. 1 ).

3.2.2 Anionic/nonionic surfactant mixture

The cmc values of anionic/nonionic surfactant mixtures were lower than those of the individual surfactants and were the lowest of all the compounds evaluated (Table 4). These findings are in agreement with those of a study conducted by Okano, who showed synergistically enhanced surface activity of anionic and nonionic surfactant mixtures $^{\text {7) }}$. The cmc of the 5:5 mixture of LAS/AE9 was lower than the values of LAS and AE9. Additionally, the cmc values of AS/AE9 and SOAP/AE9 decreased greatly when a small amount of AE9 was added. For example, the cmc of the 7:3 mixture of AS/AE9 was about $100 \mathrm{mg} / \mathrm{L}$, while that of the 10:0 mixture (AS) was about $500 \mathrm{mg} / \mathrm{L}$. Despite such synergistic increase in surface activity, the TU values of the anionic/AE9 mixtures were all greater than 1, indicating that those toxicities were less than additive. In other words, the toxicity of the anionic/AE9 mixtures decreased.

Unlike the anionic/anionic surfactant mixture, there was a distinctive trend observed in the $\gamma_{\text {tox }}$ of the anionic/nonionic surfactant mixtures. Specifically, a decrease in $\gamma_{\text {tox }}$ to values lower than those of both individual surfactants was seen in all anionic/AE9 mixtures (Fig. 3, 4 and 5). In the case of the anionic/anionic surfactant mixtures, the $\gamma_{\text {tox }}$ values of the mixtures were between the values of the individual surfactants. 
Table 4 Critical micelle concentration ( $\mathrm{cmc}$ ), 24h-EC ${ }_{50}$, and TU of anionic/ nonionic surfactant mixtures at water hardness of $25 \mathrm{ppm}$

\begin{tabular}{ccccc}
\hline & Mixed ratio & $\mathrm{cmc}(\mathrm{mg} / \mathrm{L})$ & $\mathrm{EC}_{50}(\mathrm{mg} / \mathrm{L})$ & $\mathrm{TU}$ \\
\hline LAS/AE9 & $10: 0$ & 100 & 10 & 1.00 \\
& $7: 3$ & 40 & 9 & 1.75 \\
& $5: 5$ & 30 & 9 & 1.82 \\
& $3: 7$ & 40 & 6 & 1.26 \\
& $0: 10$ & 56 & 3 & 1.00 \\
\hline AS/AE9 & $10: 0$ & 500 & 34 & 1.00 \\
& $7: 3$ & 100 & 9 & 1.09 \\
& $5: 5$ & 100 & 8 & 1.45 \\
& $3: 7$ & 56 & 6 & 1.45 \\
& $0: 10$ & 56 & 3 & 1.00 \\
\hline SOAP/AE9 & $10: 0$ & 560 & 4 & 1.00 \\
& $7: 3$ & 100 & 6 & 1.65 \\
& $5: 5$ & 100 & 4 & 1.17 \\
& $3: 7$ & 56 & 5 & 1.39 \\
& $0: 10$ & 56 & 3 & 1.00 \\
\hline
\end{tabular}

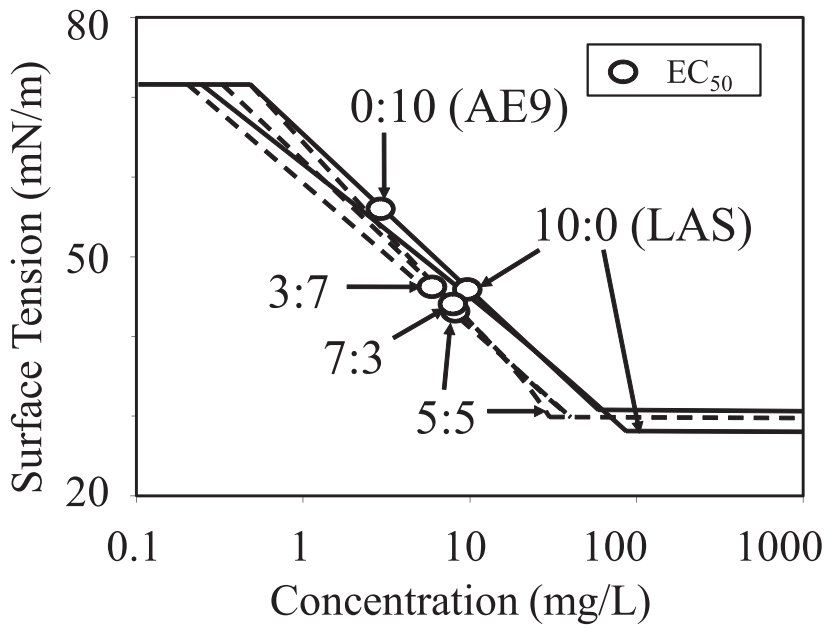

Fig. $3 \gamma$ vs concentration curves for LAS/AE9 mixtures with different mixing ratios.

Solid lines and dashed lines represent the individual surfactants and the surfactant mixtures, respectively. Circles on each curve represent the points corresponding to $\gamma_{\text {tox }}$, i.e., the surface tension at $24 \mathrm{~h}-\mathrm{EC}_{50}$.

\subsubsection{Anionic/cationic surfactant mixture}

The cmc decreased greatly, especially in the 5:5 mixture, showing an increase in surface activity (Table 5). The cmc value of the 5:5 mixture was approximately $10 \mathrm{mg} / \mathrm{L}$, while the values of LAS was $100 \mathrm{mg} / \mathrm{L}$ and that of HTAC was 180

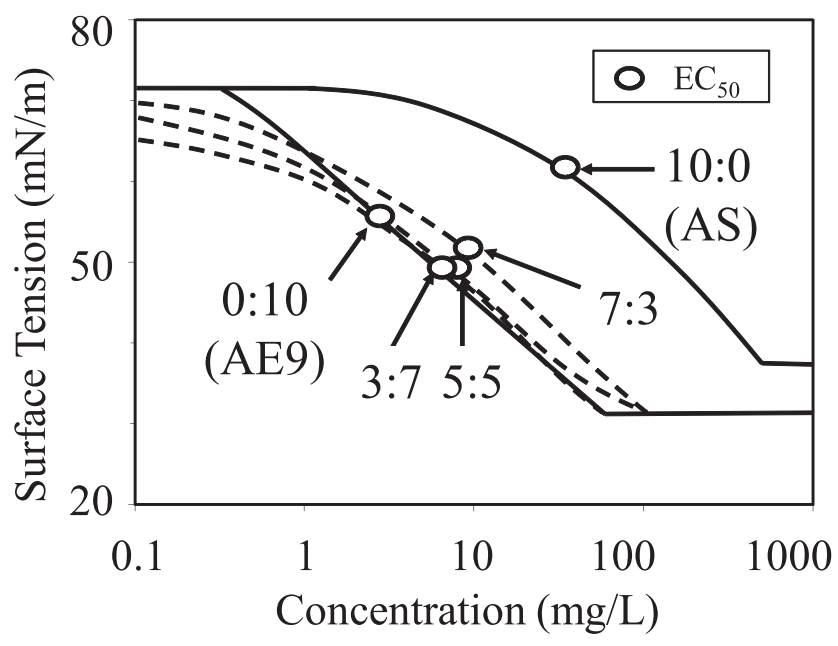

Fig. $4 \gamma$ vs concentration curves for AS/AE9 mixtures with different mixing ratios.

Solid lines and dashed lines represent the individual surfactants and the surfactant mixtures, respectively. Circles on each curve represent the points corresponding to $\gamma_{\text {tox }}$, i.e., the surface tension at $24 \mathrm{~h}-\mathrm{EC}_{50}$.

$\mathrm{mg} / \mathrm{L}$. Ogino reported that the formation of anionic-cationic complexes increases the surface activity of the anionic/cationic surfactant mixture ${ }^{9)}$. The values of TU for LAS/HTAC were greater than or equal to 1 ; therefore, the aquatic toxicities of the anionic/cationic surfactant mixtures were less 


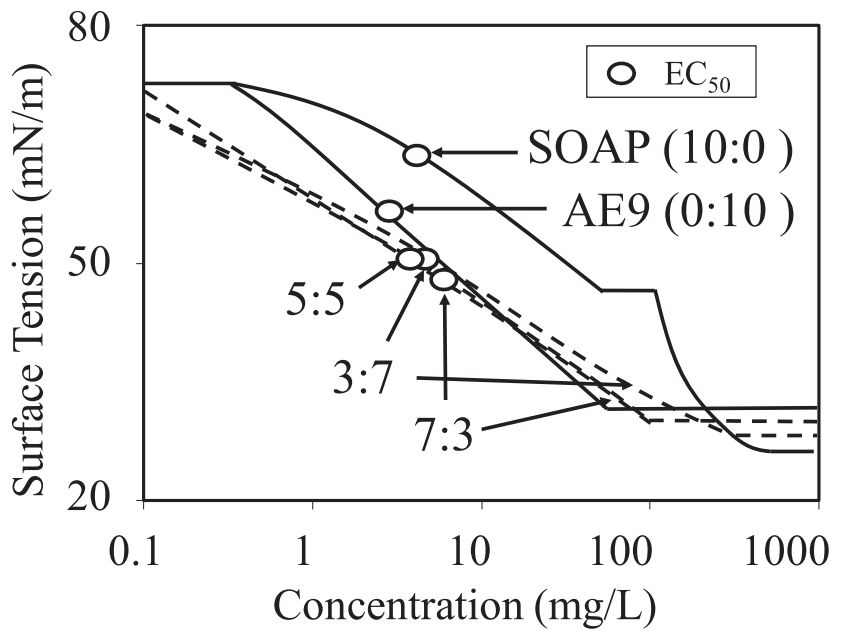

Fig. $5 \gamma$ vs concentration curves for SOAP/AE9 mixtures with different mixing ratios.

Solid lines and dashed lines represent the individual surfactants and the surfactant mixtures, respectively. Circles on each curve represent the points corresponding to $\gamma_{\text {tox }}$, i.e., the surface tension at $24 \mathrm{~h}-\mathrm{EC}_{50}$.

than additive, which was in agreement with Lewis's report (Table 5). Therefore, the increase in surface activity did not increase the toxicity of the anionic/cationic surfactant mixture.

An index of $\gamma_{\text {tox }}$ cannot be used as a toxicity indicator of anionic/cationic surfactant mixtures because the toxicity emerged before the surface tension began to decrease (Fig. 6 ). The $\gamma_{\text {tox }}$ values of the surfactant mixtures were equal to that of HTAC, which was about $72.8 \mathrm{mN} / \mathrm{m}$ (surface tension value of distilled water). These findings indicate that the main cause of the toxicity of the anionic/cationic surfactant mixtures is not the interfacial activity.

3.2.4 Effect of number of EO units on relationship between surface activity and aquatic toxicity of LAS/AE mixed systems

The LAS/AE9 mixture showed the greatest decrease in cmc among anionic/nonionic surfactant mixtures. $\mathrm{AE}$ is

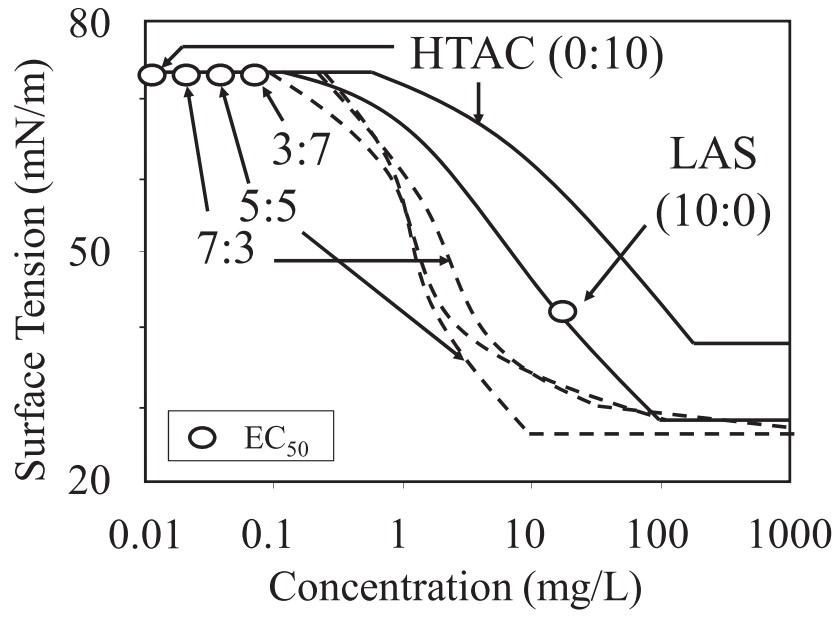

Fig. $6 \gamma$ vs concentration curves for LAS/HTAC mixtures with different mixing ratios.

Solid lines and dashed lines represent the individual surfactants and the surfactant mixtures, respectively. Circles on each curve represent the points corresponding to $\gamma_{\text {tox }}$, i.e., the surface tension at $24 \mathrm{~h}-\mathrm{EC}_{50}$.

widely used because its surface activity can be controlled by adjusting the length of the hydrocarbon chain and $\mathrm{EO}$ chain $^{14)}$. We focused on the EO chain length and its effect on the surface activity, aquatic toxicity, and $\gamma_{\text {tox }}$ of the LAS/ AE mixture.

The results revealed the same tendency in the anionic/ nonionic surfactant mixtures. Specifically, the $\mathrm{cmc}$ of the surfactant mixtures decreased below the values of the individual surfactants (Table 6). However, the decrease in the cmc value was different when the EO chain length changed. The cmc values of LAS/AE12 showed the greatest decreaase from $180 \mathrm{mg} / \mathrm{L}(10: 0)$ to $56 \mathrm{mg} / \mathrm{L}(3: 7)$. In the case of LAS/AE18, the cmc value decreased from $320 \mathrm{mg} / \mathrm{L}$ (10:0) to $100 \mathrm{mg} / \mathrm{L}(3: 7)$. The $\mathrm{cmc}$ values of LAS/AE6 only decreased from $50 \mathrm{mg} / \mathrm{L}(10: 0)$ to $40 \mathrm{mg} / \mathrm{L}(3: 7)$, which was not significant. Therefore, it can be assumed that $\mathrm{AE}$ with an EO chain length of $12(\mathrm{AE} 12)$ has the strongest interac-

Table 5 Critical micelle concentration (cmc), $24 \mathrm{~h}-\mathrm{EC}_{50}$, and TU of anionic/ cationic surfactant mixtures at water hardness of $25 \mathrm{ppm}$

\begin{tabular}{ccccc}
\hline & Mixed ratio & $\mathrm{cmc}(\mathrm{mg} / \mathrm{L})$ & $\mathrm{EC}_{50}(\mathrm{mg} / \mathrm{L})$ & $\mathrm{TU}$ \\
\hline LAS/HTAC & $10: 0$ & 100 & 10 & 1.00 \\
& $7: 3$ & 100 & 0.07 & 2.10 \\
& $5: 5$ & 10 & 0.04 & 2.00 \\
& $3: 7$ & 32 & 0.02 & 1.40 \\
& $0: 10$ & 180 & 0.01 & 1.00 \\
\hline
\end{tabular}


Table 6 Critical micelle concentration (cmc), 24h-EC ${ }_{50}$, and TU of anionic/ $\mathrm{AE}$ (EO unit length $=6,12,18$ ) surfactant mixtures at water hardness of $25 \mathrm{ppm}$

\begin{tabular}{ccccc}
\hline & Mixed ratio & $\mathrm{cmc}(\mathrm{mg} / \mathrm{L})$ & $\mathrm{EC}_{50}(\mathrm{mg} / \mathrm{L})$ & $\mathrm{TU}$ \\
\hline LAS/AE6 & $10: 0$ & 100 & 10 & 1.00 \\
& $7: 3$ & 40 & 9 & 1.16 \\
& $5: 5$ & 40 & 7 & 0.89 \\
& $3: 7$ & 40 & 5 & 0.68 \\
& $0: 10$ & 50 & 4.5 & 1.00 \\
\hline LAS/AE12 & $10: 0$ & 100 & 10 & 1.00 \\
& $7: 3$ & 56 & 18 & 1.42 \\
& $5: 5$ & 56 & 23 & 1.87 \\
& $3: 7$ & 56 & 22 & 1.78 \\
& $0: 10$ & 180 & 27 & 1.00 \\
\hline LAS/AE18 & $10: 0$ & 100 & 10 & 1.00 \\
& $7: 3$ & 80 & 14 & 1.06 \\
& $5: 5$ & 56 & 20 & 1.52 \\
& $3: 7$ & 100 & 28 & 2.13 \\
& $0: 10$ & 320 & 50 & 1.00 \\
\hline
\end{tabular}

tion with LAS.

The TU values of LAS/AE12 and LAS/AE18 were greater than 1 (less than additive), which indicates a decrease in toxicity (Table 6). Only the toxicity of the 5:5 and 3:7 mixtures of LAS/AE6 showed a slight increase in TU values to 0.89 and 0.68 , respectively. However, a great decrease in $\gamma_{\text {tox }}$ was observed in all three mixtures of LAS/AE6 (Fig. 7), LAS/AE12 (Fig. 8), and LAS/AE18(Fig. 9).

\subsection{Effect of water hardness on relationship between surface activity and aquatic toxicity}

\subsubsection{Anionic/anionic surfactant mixture}

The existence of bivalent metal ions such as calcium and magnesium increases the surface activity of anionic surfac$\operatorname{tants}^{3,5)}$. Thus, the cmc values of LAS, AS, and LAS/AS decreased significantly when tested with water with a hardness of $625 \mathrm{ppm}$ (Table 7). However, the increase in surface activity was not synergistic. Unlike the results observed when the water hardness was $25 \mathrm{ppm}$, the aquatic toxicity of LAS/AS was less than additive, showing TU values greater than 1 .

Contrary to the results observed when the water hardness was $25 \mathrm{ppm}$, a decrease in the $\gamma_{\text {tox }}$ of the LAS/AS mixtures was observed when tested with a water hardness of $625 \mathrm{ppm}$ (Fig. 10). When the water with a hardness of 25 ppm was used, this tendency was only seen for anionic/ nonionic surfactant mixtures that showed a decrease in cmc and toxicity. For hard water, the relationship between

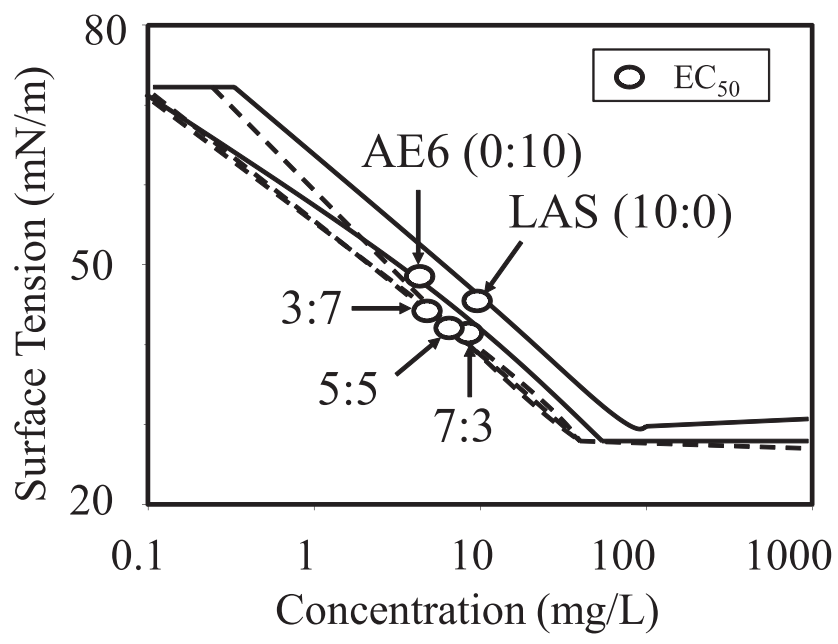

Fig. $7 \gamma$ vs concentration curves for LAS/AE6 mixtures with different mixing ratios.

Solid lines and dashed lines represent the individual surfactants and the surfactant mixtures, respectively. Circles on each curve represent the points corresponding to $\gamma_{\text {tox }}$, i.e., the surface tension at $24 \mathrm{~h}-\mathrm{EC}_{50}$.

surface activity and aquatic toxicity of the LAS/AS was similar to that of anionic/nonionic surfactant mixtures. 


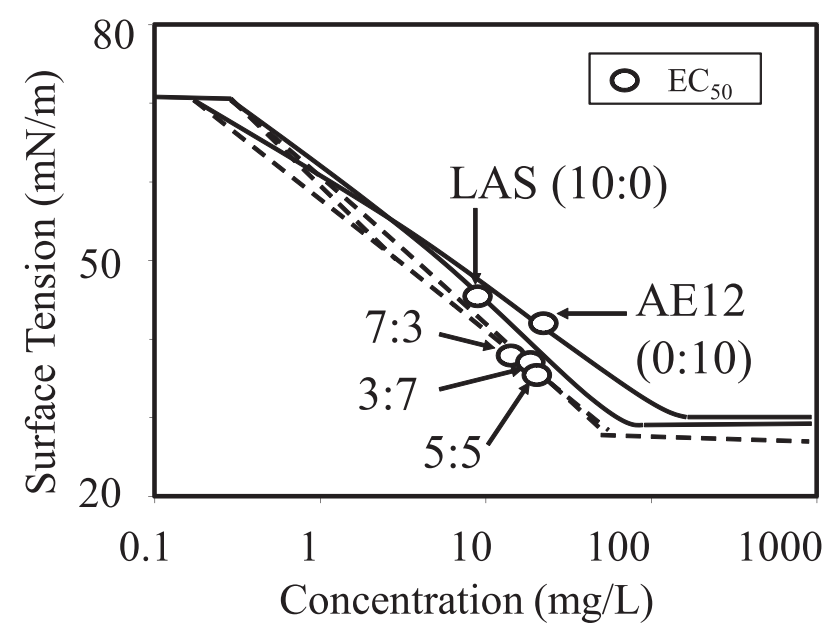

Fig. $8 \gamma$ vs concentration curves for LAS/AE12 mixtures with different mixing ratios.

Solid lines and dashed lines represent the individual surfactants and the surfactant mixtures, respectively. Circles on each curve represent the points corresponding to $\gamma_{\text {tox }}$, i.e., the surface tension at $24 \mathrm{~h}-\mathrm{EC}_{50}$.

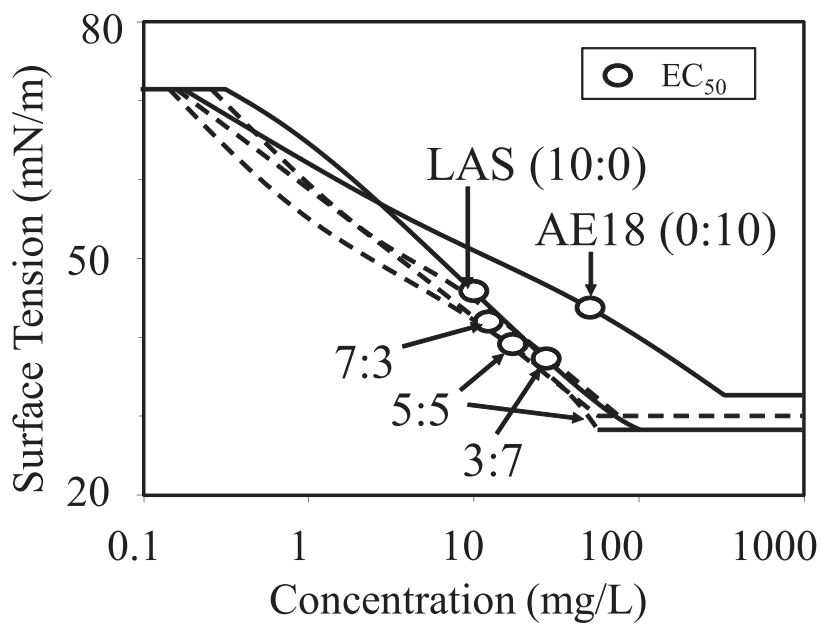

Fig. $9 \gamma$ vs concentration curves for LAS/AE18 mixtures with different mixing ratios.

Solid lines and dashed lines represent the individual surfactants and the surfactant mixtures, respectively. Circles on each curve represent the points corresponding to $\gamma_{\text {tox }}$, i.e., the surface tension at $24 \mathrm{~h}-\mathrm{EC}_{50}$.

Table 7 Critical micelle concentration (cmc), $24 \mathrm{~h}-\mathrm{EC}_{50}$, and TU of LAS/AS at water hardness of $625 \mathrm{ppm}$

\begin{tabular}{ccccc}
\hline & Mixed ratio & $\mathrm{cmc}(\mathrm{mg} / \mathrm{L})$ & $\mathrm{EC}_{50}(\mathrm{mg} / \mathrm{L})$ & $\mathrm{TU}$ \\
\hline LAS/AS & $10: 0$ & 40 & 5.5 & 1.00 \\
& $7: 3$ & 32 & 11 & 1.52 \\
& $5: 5$ & 56 & 14 & 1.52 \\
& $3: 7$ & 100 & 18 & 1.43 \\
& $0: 10$ & 100 & 28 & 1.00 \\
\hline
\end{tabular}

Table 8 Critical micelle concentration $(\mathrm{cmc}), 24 \mathrm{~h}-\mathrm{EC}_{50}$, and TU of LAS/ AE9 at water hardness of $625 \mathrm{ppm}$

\begin{tabular}{ccccc}
\hline & Mixed ratio & $\mathrm{cmc}(\mathrm{mg} / \mathrm{L})$ & $\mathrm{EC}_{50}(\mathrm{mg} / \mathrm{L})$ & $\mathrm{TU}$ \\
\hline LAS/AE9 & $10: 0$ & 40 & 5.5 & 1.00 \\
& $7: 3$ & 16 & 8.0 & 1.55 \\
& $5: 5$ & 20 & 8.8 & 1.77 \\
& $3: 7$ & 20 & 6.2 & 1.29 \\
& $0: 10$ & 45 & 4.5 & 1.00 \\
\hline
\end{tabular}

3.3.2 Anionic/nonionic surfactant mixtures

The results obtained using the anionic/nonionic surfactant mixtures were the same as those obtained using the anionic/anionic mixtures for water with hardness of 25 ppm. Additionally, synergistic decreases in cmc and toxici- ty were observed (Table 8). A decrease in the $\gamma_{\text {tox }}$ of LAS/ AE9 mixtures was also observed when tested using water with a hardness of $625 \mathrm{ppm}$ (Fig. 11). The decrease in the surface tension value at $\gamma_{\text {tox }}$ was greater in mixtures than individual surfactants. These findings indicated that $\gamma_{\text {tox }}$ of 


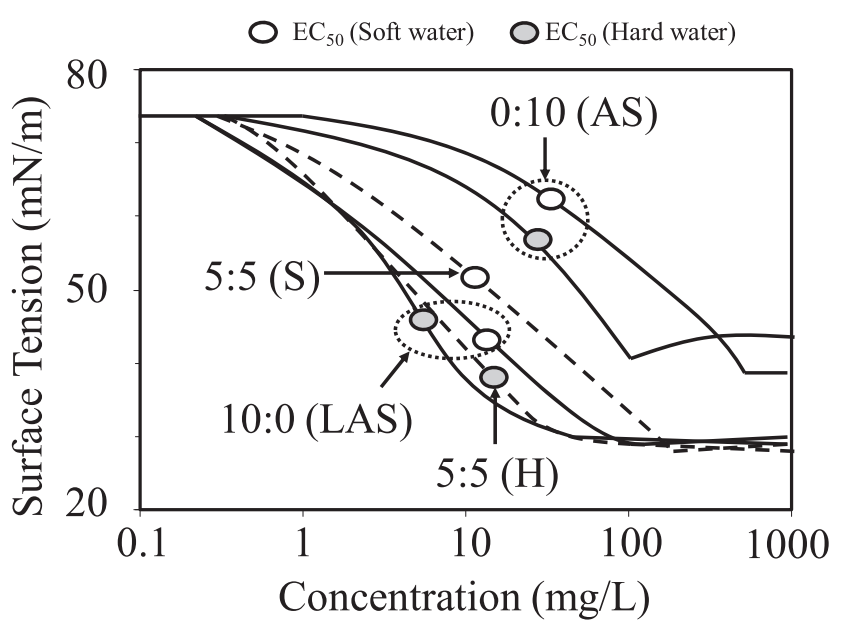

Fig. $10 \gamma$ vs concentration curves for LAS/AS mixtures with mixing ratios of 5:5 in test water with hardness of $25 \mathrm{ppm}$ and $625 \mathrm{ppm}$.

Solid lines and dashed lines represent the individual surfactants and the surfactant mixtures, respectively. Circles on each curve represent the points corresponding to $\gamma_{\text {tox }}$, i.e., the surface tension at $24 \mathrm{~h}-\mathrm{EC}_{50}$.

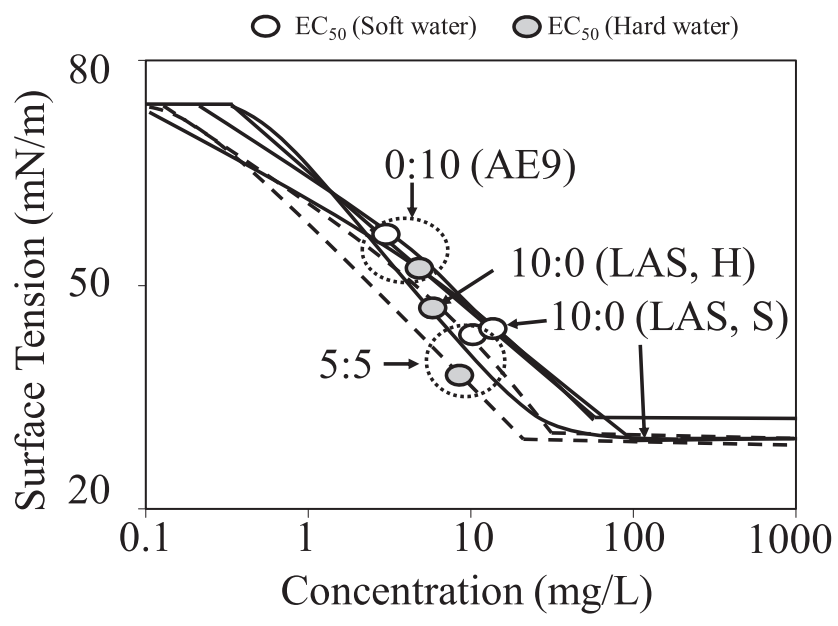

Fig. $11 \gamma$ vs concentration curves for LAS/AE9 mixtures with mixing ratios of 5:5 in test water with hardness of $25 \mathrm{ppm}$ and $625 \mathrm{ppm}$.

Solid lines and dashed lines represent the individual surfactants and the surfactant mixtures, respectively. Circles on each curve represent the points corresponding to $\gamma_{\text {tox }}$, i.e., the surface tension at $24 \mathrm{~h}-\mathrm{EC}_{50}$.

Table 9 Critical micelle concentration $(\mathrm{cmc}), 24 \mathrm{~h}-\mathrm{EC}_{50}$, and TU of LAS/ HTAC at water hardness of $625 \mathrm{ppm}$

\begin{tabular}{ccccc}
\hline & Mixed ratio & $\mathrm{cmc}(\mathrm{mg} / \mathrm{L})$ & $\mathrm{EC}_{50}(\mathrm{mg} / \mathrm{L})$ & $\mathrm{TU}$ \\
\hline LAS/HTAC & $10: 0$ & 40 & 5.5 & 1.00 \\
& $7: 3$ & 18 & 0.42 & 3.99 \\
& $5: 5$ & 10 & 0.75 & 11.79 \\
& $3: 7$ & 56 & 0.11 & 2.41 \\
& $0: 10$ & 70 & 0.03 & 1.00 \\
\hline
\end{tabular}

the LAS/AE9 mixtures is more easily affected by the water hardness than LAS and AE9.

\subsubsection{Anionic/cationic surfactant mixture}

Similar to the results obtained when water with a hardness of $25 \mathrm{ppm}$ was used, cmc values of 7:3 and 5:5 mixtures synergistically decreased below the values of LAS and HTAC when the water hardness increased (Table 9). The surface activity also synergistically increased in mixtures, but the surface tension curve and cmc value of the 5:5 mixture was not affected by the water hardness when compared to the results obtained when water with a hardness of 25 ppm was used (Fig. 12). Conversely, the aquatic toxicity of the 5:5 mixture was greatly affected by the water hardness, showing a significant increase in TU value (Table 9). The TU of the 5:5 mixture was about 12 , while the value of the $7: 3$ mixture was 4 and that of the $3: 7$ mix- ture was 2.4. Since no significant change in the surface tension was observed, it can be assumed that molecules of the LAS/HTAC complex in the bulk phase were affected by the existence of metal ions, which caused the decrease in toxicity. Although the mechanism of the decrease in toxicity is not clear, it is a very interesting and noteworthy phenomenon associated with the toxicity of mixtures of surfactants.

\section{CONCLUSION}

In this study, we discussed a new perspective for assessing the aquatic toxicity of surfactants on a laboratory scale by considering the surface activity of surfactant mixtures as the main cause of toxicity. The relationship between the surface activity and aquatic toxicity of anionic/anionic, an- 


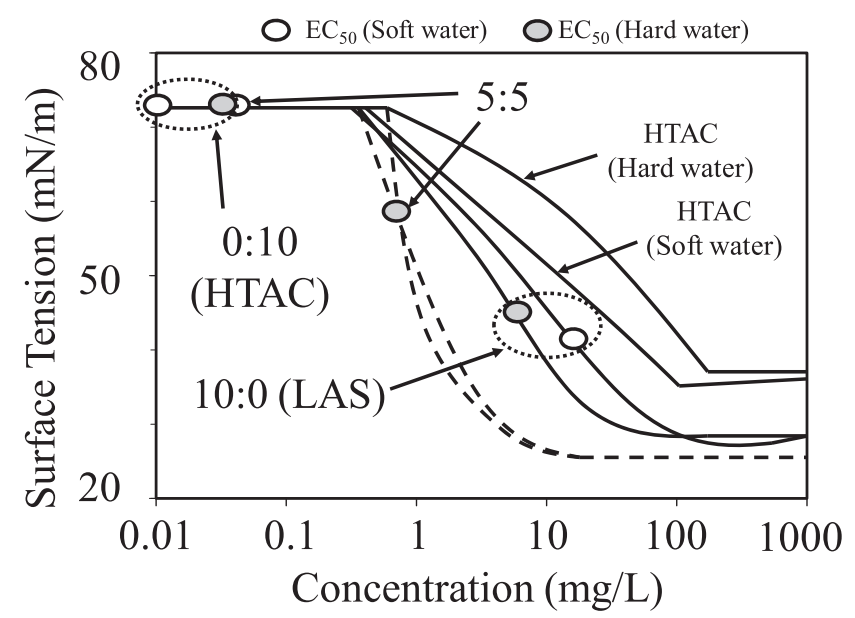

Fig. $12 \gamma$ vs concentration curves for LAS/HTAC mixtures with mixing ratios of 5:5 in test water with hardness of $25 \mathrm{ppm}$ and $625 \mathrm{ppm}$.

Solid lines and dashed lines represent the individual surfactants and the surfactant mixtures, respectively. Circles on each curve represent the points corresponding to $\gamma_{\text {tox }}$, i.e., the surface tension at $24 \mathrm{~h}-\mathrm{EC}_{50}$.

ionic/nonionic, and anionic/cationic surfactant mixtures was investigated. $\gamma_{\text {tox }}$ was used as a toxic indicator to represents the surface tension at the point at which toxicity emerges $\left(24 \mathrm{~h}-\mathrm{EC}_{50}\right)$.

The relationship changed in response to the ionic combinations of the surfactants, but similar tendencies were observed for each combination. The changes in the surface activity, aquatic toxicity, and $\gamma_{\text {tox }}$ of each mixture in test water with hardness of $25 \mathrm{ppm}$ and $625 \mathrm{ppm}$ are shown in Table 10. We established the relationship between the surface activity and aquatic toxicity of binary surfactant mixtures and found that an increase in the surface activity did not necessarily increase the toxicity of the surfactant mixture. Instead, the aquatic toxicity of most of the surfactants decreased in the mixtures.

\section{ACKNOWLEDGEMENT}

This study was partially supported by a Grant-in-Aid for Scientific Research (A) from the Ministry of Education, Science, Sports and Culture $(21240066,2009)$.

\section{References}

1. Calamari, D; Marchetti, R. The toxicity of mixtures of metals and surfactants to rainbow trout (salmo gairdneri rich.), Water Res. 7, 1453-1464(1973).

2. Lewis, M. A. The effects of mixtures and other environmental modifying factors on the toxicities of surfactants to freshwater and marine life. Water Res. 26, 1013-1023 (1992).

3. Tovell, P. W. A.; Newsome, C.; Howes, D. Effect of water hardness on the toxicity of an anionic detergent to fish. Water Res. 8, 291-296(1974).

4. Tovell, P. W. A.; Newsome, C.; Howes, D. Effect of water hardness on the toxicity of a nonionic detergent to fish. Water Res. 9, 31-36(1975).

5. Oya, M.; Orito, S.; Ishikawa, Y.; Iizuka, T. Effect of water hardness and existence of adsorbent on toxic sur-

Table 10 Summary of the relationship between surface activity and aquatic toxicity of anionic/anionic, anionic/nonionic, and anionic/cationic surfactant mixtures

\begin{tabular}{|c|c|c|c|c|}
\hline Ionicity & Water hardness & Surface activity & Aquatic toxicity & $\gamma$ tox \\
\hline \multirow{2}{*}{$\begin{array}{l}\text { Anionic (-) } \\
\text { Anionic(-) }\end{array}$} & $25 \mathrm{ppm}$ & $\rightarrow$ & $\begin{array}{cc}\nearrow & \mathrm{LAS} / \mathrm{AS} \\
\searrow & \mathrm{LAS} / \mathrm{SOAP}\end{array}$ & $\rightarrow$ \\
\hline & $\begin{array}{l}625 \mathrm{ppm} \\
(\mathrm{LAS} / \mathrm{AS})\end{array}$ & $\rightarrow$ & $\searrow$ & $\searrow$ \\
\hline \multirow[t]{2}{*}{$\begin{array}{c}\text { Anionic }(-) \\
\text { Nonionic }( \pm)\end{array}$} & $\begin{array}{c}25 \mathrm{ppm} \\
\text { (Include change in } \\
\text { EO unit length) }\end{array}$ & $\nearrow$ & $\begin{array}{l}\text { LAS/AE6 } \\
\text { LAS/AE12 } \\
\text { LAS/AE18 }\end{array}$ & $\searrow$ \\
\hline & $\begin{array}{c}625 \text { ppm } \\
\text { (LAS/AE9) }\end{array}$ & $\nearrow$ & $\searrow$ & $\searrow$ \\
\hline \multirow{2}{*}{$\begin{array}{l}\text { Anionic (-) } \\
\text { Cationic (+) }\end{array}$} & $25 \mathrm{ppm}$ & $\nearrow$ & $\searrow$ & Not related \\
\hline & $625 \mathrm{ppm}$ & $\nearrow$ & $\searrow$ & Not related \\
\hline
\end{tabular}


face tension of surfactants for aquatic species. J. Oleo Sci. 56, 237-243 (2007).

6. Senzai Senjyou Hyakkajiten (Minagawa, M; Fujii, T.; Oya, M. ed.) Asakura syoten. Tokyo. Jpn. pp.838-841 (2003).

7. Okano, T.; Abe, Y.; Hotta, D.; Nakano, T.; Sugihara, G.; Oh, S. Binary mixed systems of anionic/nonionic surfactants: synergistically enhanced surface activity and relationship among compositions of monomers in bulk $\left(X_{2}\right)$, micelles $\left(Y_{2}\right)$ and adsorbed film at air/water interface $\left(Z_{2}\right)$. J. Oleo Sci. 49, 915-928(2000).

8. Abe, M.; Ogino, K. Mixed Surfactant Systems. Marcel Dekker Inc. NY. pp.1-21 (1993).

9. Ogino, K. Solution properties of mixed surfactant systems. J. Jpn. Oil Chem. Soc. 34, 568-575(1985).

10. Lewis, M. A.; Perry, R. L. Acute toxicities of equimolar and equitoxic surfactant mixtures to Daphnia magna and Lepomis macrochirus. Aquatic Toxicology and Hazard Assessment: Fourth Conference. (Branson D.
R.; Dickson K. L. ed.) ASTM STP 737, pp.402-418 (1981).

11. Sprague, B. J. Measurement of pollutant toxicity to fish. II. Utilizing and applying bioassay results. Water Res. 4, 3-32 (1970).

12. Kodama, M.; Yamamoto, T.; Oikawa, K.; Kitano, M. Effects of surfactants on the toxicity of chemical substances acting on Daphnia ( $2^{\text {nd }}$ report) Toxicity when chemical substances and surfactants coexist. Jpn. J. Environ. Toxicol. 6, 31-43(2003)

13. Kikuchi, M; Wakabayashi, M. Lethal response of some surfactants to medaka Oryzias latipes with relation to chemical structure. Bull. Jpn. Soc. Sci. Fish 50, 1235-1240 (1984).

14. Cox, M. F. Effect of alkyl carbon chain length and ethylene oxide content on the performance of linear alcohol ethoxylates. J. Am. Oil Chem. Soc. 66, 367-374 (1989). 